\title{
Ecological Landscape Planning Considering Landscape Aesthetics (Case Study: Part of Tehran-Qom Freeway)
}

\author{
Hassan Darabi*, Shoukoofeh Sadat Razavi, Azar Vaeziheir \\ Faculty of Environment, University of Tehran, Tehran, Iran \\ Email: ^darabih@ut.ac.ir, sh.razavi@ut.ac.ir, azar.vaeziheir@ut.ac.ir
}

How to cite this paper: Darabi, H., Razavi, S.S. and Vaeziheir, A. (2017) Ecological Landscape Planning Considering Landscape Aesthetics (Case Study: Part of Tehran-Qom Freeway). Open Journal of Ecology, 7, 503517.

https://doi.org/10.4236/oje.2017.79034

Received: June 28, 2017

Accepted: August 2, 2017

Published: August 5, 2017

Copyright $\odot 2017$ by authors and Scientific Research Publishing Inc. This work is licensed under the Creative Commons Attribution International License (CC BY 4.0).

http://creativecommons.org/licenses/by/4.0/

(c) (i) Open Access

\begin{abstract}
Visual quality is a significant issue in today's modern world which needs to be evaluated. This assessment is based on the observer's perception and sight of space and attempts to introduce the criteria of spatial desirability in the landscape. Analysis of the relationships between visual quality and structural features of the landscape is an effective way of conducting cognitive research. For this purpose, the analysis of visual quality was considered by compiling measurement and evaluation criteria, based on the concept of user preferences, in the part of Tehran-Qom Freeway, near the northeastern side of Imam Khomeini International Airport (Iran). The main objective of this research is to present a strategic plan for preserving and restoring the ecological landscape, creating a sense of place in the region, emphasizing gradual changes in the landscape during the movement and considering its relation to landscape aesthetics. For this purpose, after the questionnaire was prepared, the classifying visual quality method (Q-Sort) was used. Finally, using the results obtained from landscape analysis, identifying the components which led to the lack of visibility of individuals, and by using the geographic information systems (GIS), the strategic design of the area was designed.
\end{abstract}

\section{Keywords}

Ecological Landscape, Strategic Planning, Aesthetics, Visual Quality, Landscape Perception, Q-Sort

\section{Introduction}

The general sensitivity to the landscapes is one of the first and perhaps the most important catalysts of environmental action and awareness. In 1969, Elwood Schaffer posed a question that created the field of research for perceptual vision: 
"Why is a landscape more preferable than another?"

Identifying quantitative variables in a natural landscape which is significantly related to public priorities in a landscape is of significance. By a little knowledge about attributes which will affect aesthetic appealing in a landscape, natural resource planners can decide about creating, developing or maintaining these features, on the basis of reality [1].

This approach to assessing landscape perception is based on a kind of causal relationship between landscape changes created on the ground and the perception of landscape value. In this linkage, which includes several assumptions, the planners and managers of region will develop and implement the plans and actions which make the landscape change. These changes are coordinated and expanded by planners and managers in a specific area. They usually show their goals using maps or other spatial representations.

It is important to do such studies because the findings can change both in response to changes in the norms and expectations of society, and as a result of changing in a landscape [2]. One of the most important factors in dealing with the natural environment, especially in the tourism and recreation industry, is the landscape quality. Considering the growing population, the development of urban areas, the excessive pollution of the environment, the general demands for the integrity of natural resources, especially the attention to the beauty of landscapes around the cities, has significantly increased.

Visitors use the paths for a variety of reasons. In designing routes, it is very important to take into account the users' priorities in determining their walkway destination [3] [4].

According to the fact that environmental beauty is an important motivator for environmental protection, in the decision making and management of critical areas [5], the environment image should be considered as a source and eventually as a variable [6].

Therefore, managers of important regions, environmentalists, government agencies and environmental organizations are required to use scientific tools in environmental image assessment [7]. Expectations of beauty and aesthetics should also be considered as part of a think tank design [8]. Accordingly, the methods of environmental image analysis at the planning level are one of the most important steps to achieve the goal of preserving natural values. Scenery assessment involves examining the existence and assessment of various visual features of the environmental image for planning purposes, design and management. Scenery assessment involves examining the existence and assessment of various visual features, environmental image for planning purposes, design and management [9].

Over the past few decades, different approaches have been developed to assess the quality of environmental image. The two methods of environmental image assessment include the specialized approach and perceptual approach. In the specialized approach, the visual quality of the environment image is defined by physical and biological values. While in the perceptual approach, the visual as- 
sessment of the environmental image is the result of visual structures of the environment image in the sight of human, which is in contrast to the psychological processes (perceptual, cognitive, and emotional) [1] [8]. The perceptual approach expresses the beauty of the environment image as a product of the human mind based on an interpretation of what has been received [10].

Today, the goal of landscape visual quality evaluation is to identify the criteria by which we can protect, restore and revive the landscape. In this way, it is possible to preserve landscapes that are beautifully suitable and, if necessary, restore the landscapes [11].

The expectations of beauty and aesthetics should be considered as part of a think tank design and planning. To achieve this goal, a thorough understanding of the visual and non-visual environmental beauty is needed. Today, managing and protecting the environment with beautiful landscapes is one of the important criteria in the establishment and maintenance of protected areas. The analysis of environment visual quality system has an important place in the design and planning of the environment [12].

So far, various theories have been presented about landscape visual quality assessment. Kaplan \& Kaplan [13] is one of the broadest theories studied in environmental psychology and landscape visual quality assessment (Kaplan and Kaplan's perceptual model).

Landscape preferences theory is one of the theories in this model. This theory states that users after being in setting (space) have two main needs: one is the understanding of the space, and the other is to explore and search in space [14]. In addition, users may have a quick understanding of the environment or, as a result of movement in the space they will gradually understand the environment.

The image of an external environment, either natural or constructed, is directly understood by the person who visits or uses the environment. An environment with beautiful landscapes is one part of the overall environment, which is seen from a prominent point on one hand [8]. The beauty of the environment is one of the benefits and strengths of the recreational areas, and is a useful factor in promoting the tourism industry in the area. Therefore, the beauty of environmental resources should be used as far as possible for recreation and tourism industry. In this regard, the scenery and points of viewing the nature are amongst the significant elements that visitors are considering in choosing a recreational route [15].

In large cities, landscape users are faced with a variety of visual contamination which has a large impact on visual quality [16]. Landscape dynamics is one of the important features, which illustrates changes in the spatial and functional frame in the landscape, within a given time. Most of the paradigmatic analysis of the landscape has not dealt with the various dimensions of information and criteria, especially in certain topographic fields, and most of these observations have not been measured. That is why they bring in irrefutable results [17].

Nowadays, people's needs and reactions to their surroundings can be examined not only by sociologists but also by landscape architects, urban planners, 
and all those who involved in the design of human environments. In this regard, the creation of a sense of place in a space which is designed for a popular community is very effective in how people of that society use and love that spaces [18].

As mentioned earlier, the use of landscape analysis data to identify user preferences and to apply the criteria identified in the design is a new method. Most research is acted according to an island method. The use of landscape analysis results is not very common in design. Now the question arises that whether the user preferences of landscape can be used in environmental design? How can user-centric desirability criteria be identified?

In this study, we have tried to present a strategic plan, draw an ecological landscape, create a sense of place in the area, emphasize the gradual changes of the landscape during the movement, and its relation with the landscape aesthetics.

\section{Materials and Methods}

\subsection{Study Area}

The study area is located between $35^{\circ} 24^{\prime} 27^{\prime \prime}$ to $35^{\circ} 26^{\prime} 19^{\prime \prime}$ latitudes and $51^{\circ} 12^{\prime} 23^{\prime \prime}$ to $51^{\circ} 12^{\prime} 28^{\prime \prime}$ longitudes with an average elevation of 1050 meters, which is part of the southern lands of Tehran, next to Tehran-Qom (Persian Gulf) Free Way, near Imam Khomeini International Airport (in Iran), which is of great economic and recreational status, which a small part of it is located in the plain area, and most of it is located in the plateau area, were examined.

The part that is located in the plain area has a fertile soil, which is encountered in some areas with flood constraints. The lands of the plateau area have gypsum soils with medium to large pebbles, which in some areas lime layers are placed on a layer of gypsum. The study area is shown in Figure 1.

Tehran features a semi-arid climate with continental climate characteristics and a Mediterranean climate precipitation pattern. It can be generally described as mild in spring and autumn, hot and dry in summer, and cold and wet in winter.

Average annual temperature of the area is $17.5^{\circ} \mathrm{C}$, Average annual precipitation of the area is $233.5 \mathrm{~mm}$ and Average relative humidity is $40 \%$ [19].

The climate of Tehran province in the southern areas is warm and dry and due to climate, soil and topographic factors, vegetation is of desert type.

Most of the annual light precipitation occurs from late autumn to mid-spring, so the time of study was the autumn of 2016 .

\subsection{Landscape Analysis Based on the Analysis of Visual Elements in the Landscape}

The elements of the landscape constructor, their changes in the environment and the spatial characteristics that appear in their mutual interaction, together lead to a landscape analysis based on thinking [20]. In the scope of the study, 


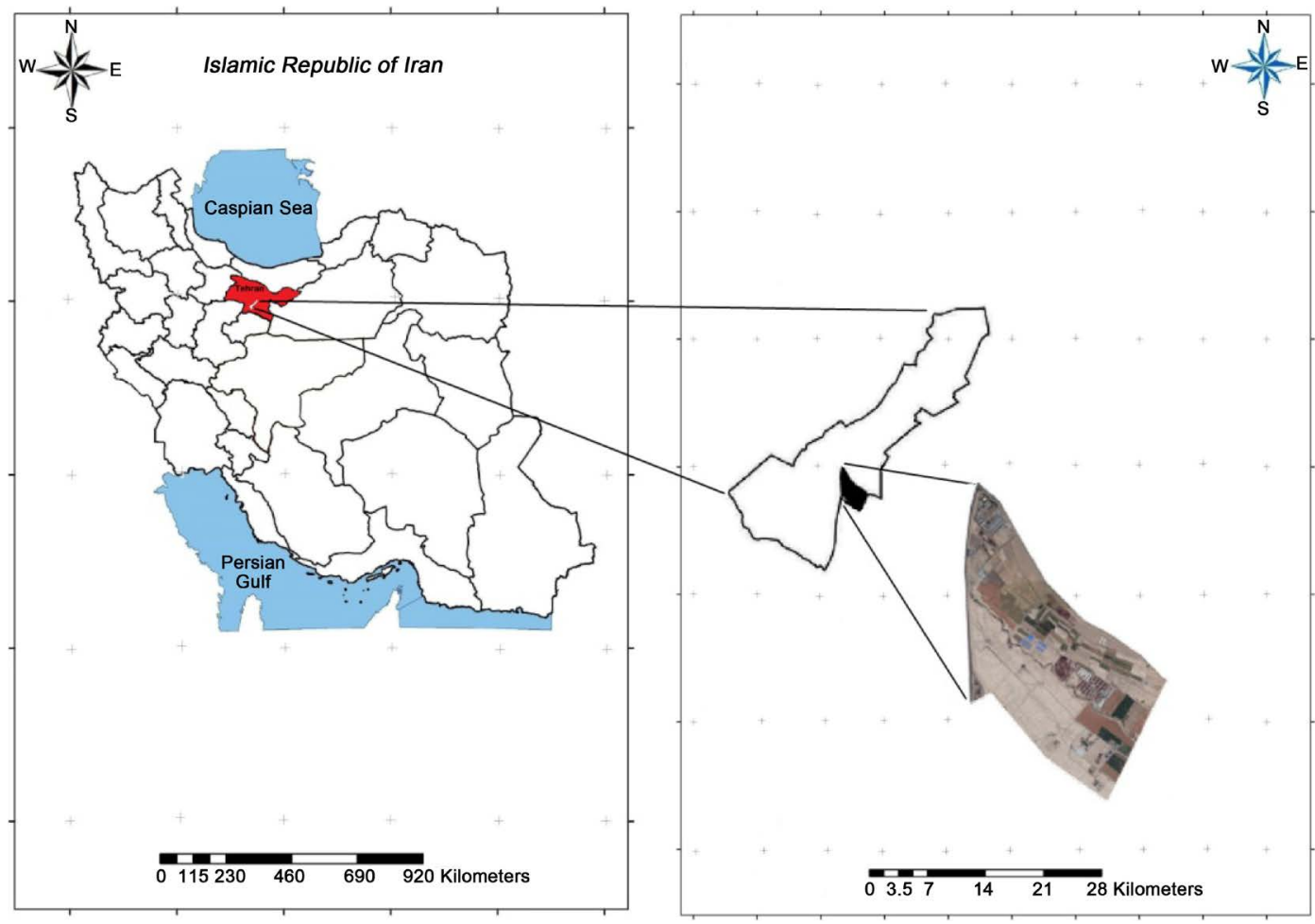

Figure 1. The study area.

five visual types can be identified in terms of visual characteristics. The quality of the visual qualities of each type covers a wide range of environmental, ecological, social and cultural factors (landscape typography is done based on the existence or absence of vegetation and existing uses):

a) The agricultural landscape: In agricultural landscape view, due to the presence of prominent elements, landscape-maker variables are very favorable, and due to the presence of landscape layers (visibility to the surrounding), the landscape quality is optimal. In some areas, which include a large part of the range, the texture is uniform and lacks visual diversity. In this type of landscape, the presence of tall and solid trees creates a sense of place in the landscape.

b) The industrial landscape: This type of landscape includes livestock, animal husbandry and small industrial workshops. Visually, this type of landscape is of low quality. Because this type of landscape, in addition to creating various visual contaminants, it causes disturbances in the natural and agricultural landscape. The significant issue in this kind of landscape is the presence of contaminants which affect the environment. The best solution for solving this problem seems to be the control of pollution and creation of visual consistency in this type of scenery.

c) The natural landscape: This landscape includes green spaces which has been sowed by hand, the green spaces on the area which are wild plants, arid lands and natural lands, which have a high visual quality. This type of landscape also, brings together the various environments in the region, and shows the identity and readability of the area. In some paths, by creating a natural tree 
cover, the legibility of the path and the sense of place in the environment can be made. Strengthening and focusing on this type of landscape brings out more visual appeal of the region. In the case of arid lands, the most important issue is the erosion of wind and water, which will lead to the loss of fertile soil and many problems.

d) The landscape of the Shore River: This landscape extends from the northwest to the southeast of the site. Almost $90 \%$ of this river is completely destroyed in the dry seasons. However, a special ecosystem has been created around this river, which attracts the animals, especially birds and insects. The diversity of vegetation which we can see on the floor of this river is high. Maintaining and rehabilitating the river is one of the most considerable points which can help prevent wind erosion.

e) The service welfare landscape: This type of landscape includes a gas station and a service complex. The presence of this landscape is very important with regard to the location of the region (the route of the Imam Airport to the entrance of Tehran metropolis). The shortage of this type of landscape along Qom -Tehran freeway is an important issue. Thus, by integrating the natural landscape type and the service welfare landscape type with each other, we can achieve the overall integrity of the landscape. Of course, considering the overall design goal based on the principles of sustainable development, we must pay attention to the various contaminants resulting from the types of service users. With the proper planning, attracting tourists and providing them with a welfare service, environmental pollution can also be prevented.

\subsection{Research Methodology}

\section{What is Q-sort?}

Q-sort is a general name used by William Stephenson to identify a set of philosophical, psychological, statistical, and psychometric ideas which are focused on individual research. The Q-sort method is a suitable method for testing concepts and theories that are used by respondents with common features. This approach is an innovative approach to qualitative analysis that is presented through a mental pattern. Therefore, it shed light on the point of views on a particular topic, and while allows to distinguish the delicate differences, it also allow to differentiate among the main differences [21]. One of the strengths of this method is the availability of analytical and statistical facilities, close relationship with the theory, the suitability for comprehensive study of the individual, the appropriateness of testing the effect of independent variables on complex variables, the utility of exploratory research, and finding new ideas and hypotheses [22].

This method is used to rank the items examined (phrase, sentence, photo, news, etc.) using a scale such as the "Likert scale", and then the correlation between the responses of different individuals is being focused according to this ranking. In this method, the checked items are written or printed on cards which are named $\mathrm{Q}$ cards. Then, these cards are administered to the respondents. Finally, these examined items are distributed on the Likert scale cards, in the order 


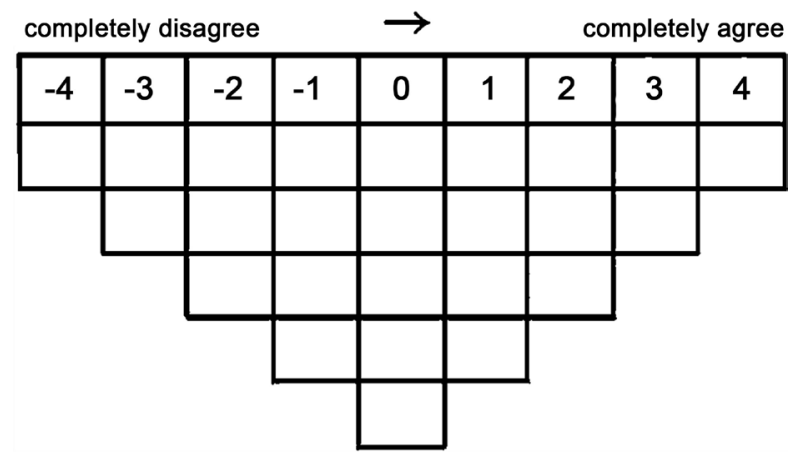

Figure 2. A sample of Q diagrams with pseudo normal distribution [22].

that the researcher determines, in such a way that the distribution of the frequencies is normal.

The $\mathrm{Q}$ chart is a big chart which is administered to a person to identify his/her desired choice order by placing cards on it. The ordering of the examined items distribution on scale cards or, in other words, the ranking of the examined items varies according to the objectives of the research. A sample of $\mathrm{Q}$ diagram is shown in Figure 2.

In the examination of the area under study, the basis for assessing was a perceptual approach and the evaluation was done based on the observer view. Thus, spectacular views of the nature in the region were recorded using a camera and GPS.

At the first stage, a basic analysis of texts, articles and Internet resources was developed to formulate theoretical foundations. Then, in order to know the characteristics of the area, other sources such as maps and aerial photographs were studied. In order to complete the information, local users were asked to respond to the questionnaire prepared in this regard.

The preferences of users in this study were done using the visual quality classification method. This method was first used by William Stephenson in psychology. Afterwards, the development of this method over time has transformed this method into one of the most widely used measurement methods in other sciences.

Subsequently, the zoning of the area under study was carried out based on available uses and facilities, and the zoning boundaries were determined based on the differences in each area. After that, according to the method used in the analysis (Q-sort), it was taken photos from each zone. At the following, people expressed their opinions on each picture.

The number of photographs taken from each zone should be equal. For example, 2 photos should be taken from any area. The selection of photographs should be in a way that the characteristics of the beauty of those that are not of the desired quality or are similar, distributed uniformly, display various landscape features, have criteria such as background, quality of vision, natural elements such as vegetation (species of plants).

Then the photos are placed in the questionnaire. In fact, the photos are the questions in the questionnaire, which people see and tell their opinion about the beauty of the spaces. The questionnaire was graded in the Likert spectrum and it 
range from grades like quite beautiful, beautiful, ordinary, unpleasant, totally unpleasant).

Afterwards, with regard to the abundance of choices obtained from the people in each photo, the average score of the beauty of each photo was calculated in each zone. The average number of extracted figures represents the level of desirability in the perspective of viewers.

Using the results of landscape analysis, spatial utility criteria were identified from the user's point of view, and the required measures to achieve these criteria were developed and used in design. At the final stage, a strategic plan was developed in ArcGIS software.

Perception of environment aesthetics is basically visual and germane to the beauty. Despite this experience, the different environments cover all our senses, and in some cases hearing, smelling and touch can be more important than vision.

The visual perception of urban environments is the product of perception and recognition, and it is what prompts us to understand how to interpret them, how to interpret and judge the aggregated information, and how the space is attractive in our minds [23].

At first, the area was studied in terms of existing uses then a map of existing uses in the region was produced which is shown in Figure 3.

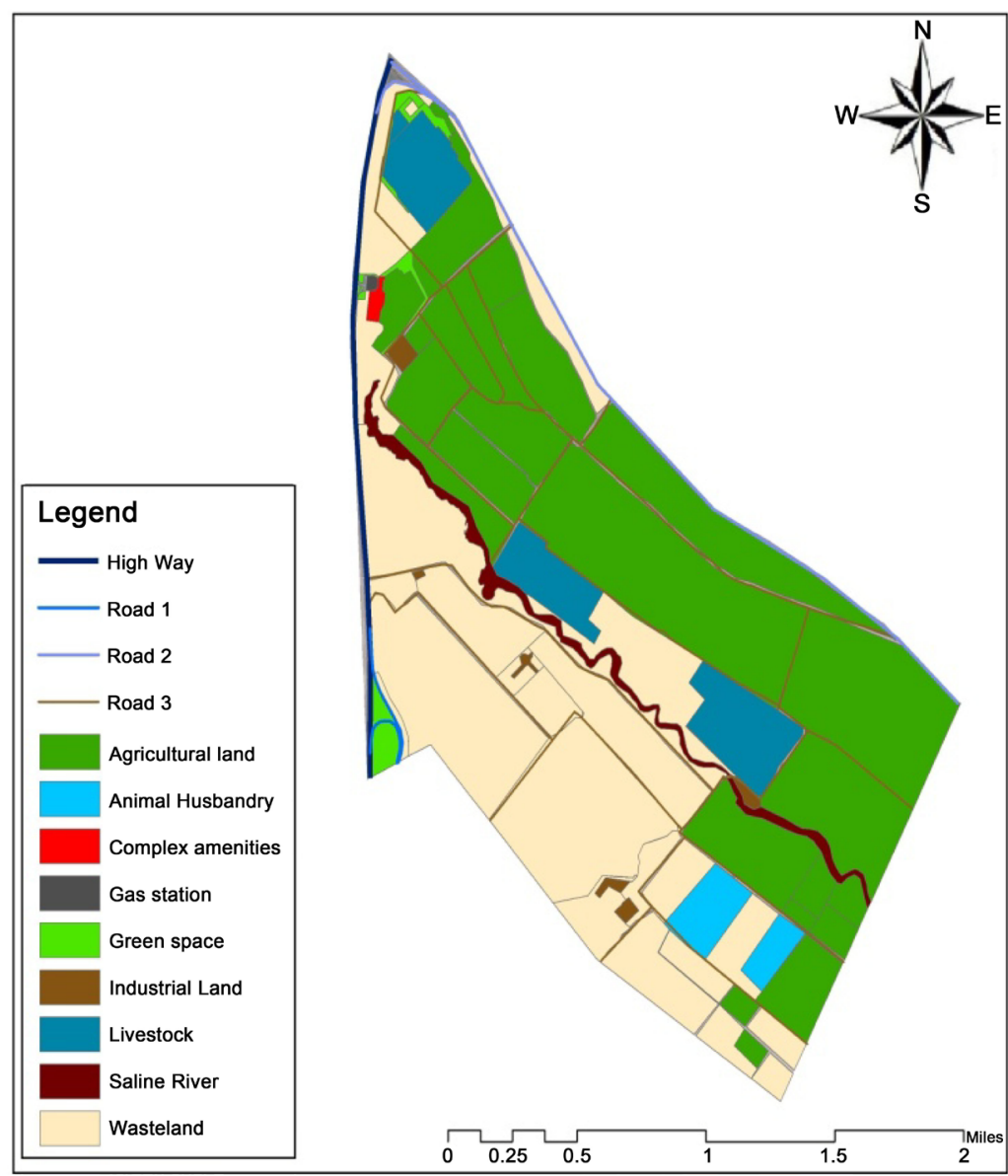

Figure 3. Existing uses map of study area. 


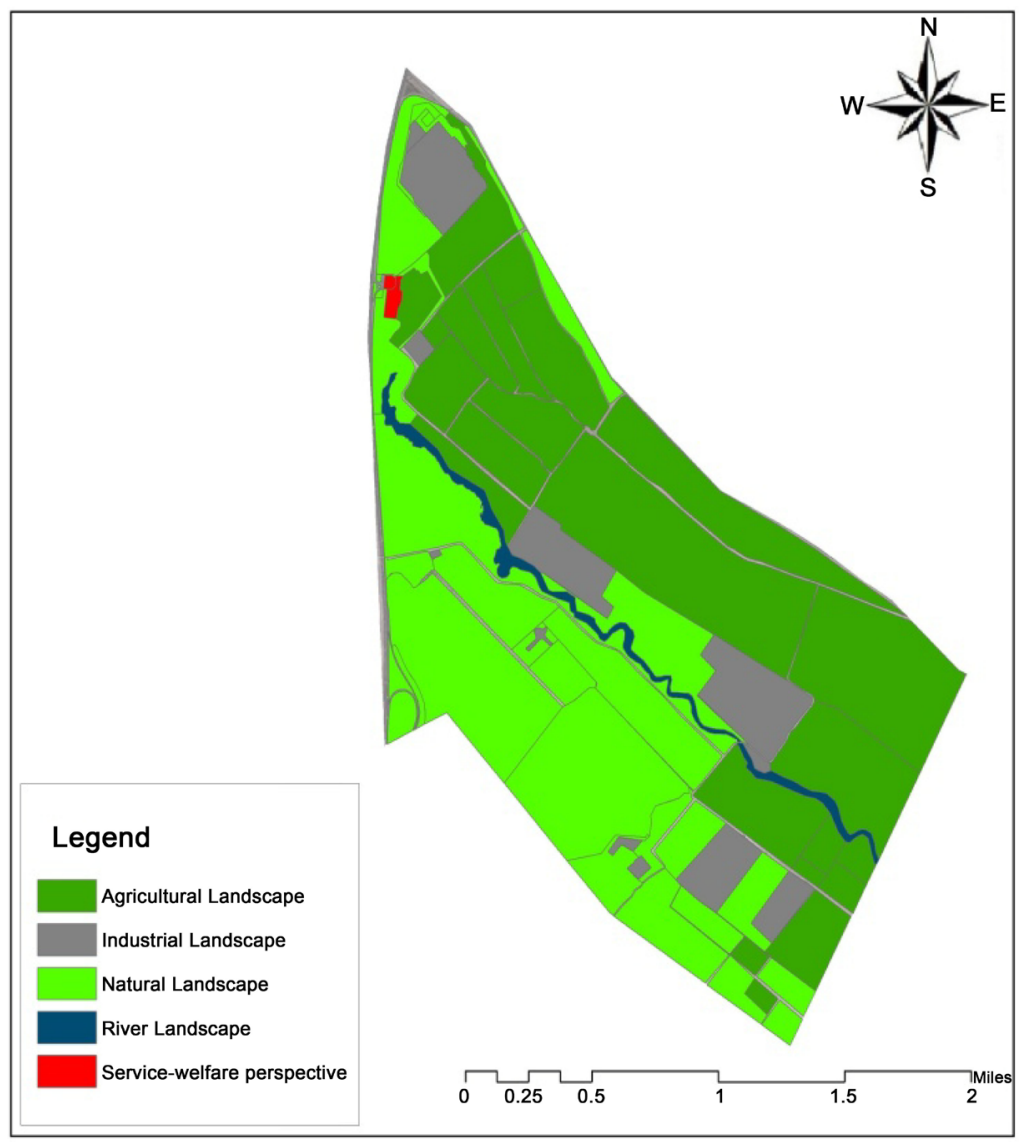

Figure 4. Landscape zoning map of study area.

In the next step, according to the map of existing uses in the region and landscape analysis by Simon Bell Method, a landscape zoning map was prepared which is shown in Figure 4.

Then, in each zone, 2 photographs were taken and placed in the questionnaire. The photographs are shown in Figure 5. Then the users were asked to register their points on the cards according to the visual characteristics of each photo.

The rating of each photo in the questionnaire was ranged in this way: very nice, beautiful, ordinary, ugly and very ugly. Score considered for very beautiful grade was +2 and score for very ugly was -2 . Thereafter, we calculated the average scores for each photo. The following formula was then used to calculate and summarize the scores of each photo:

$$
N=\sum_{i=1}^{5} n_{i}(3-i)
$$

$N$ : Total score of each photo

$n_{1}$ : The number of people choosing very beautiful choice

$n_{2}$ : The number of people choosing beautiful choice

$n_{3}$ : The number of people choosing normal choice

$n_{4}$ : The number of people choosing ugly choice

$n_{5}$ : The number of people choosing very ugly choice 


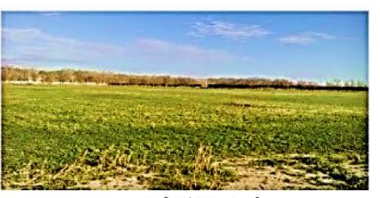

picture 1

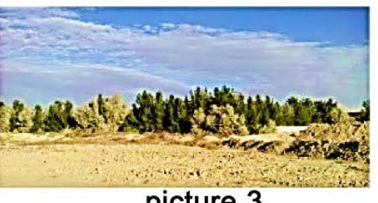

picture 3

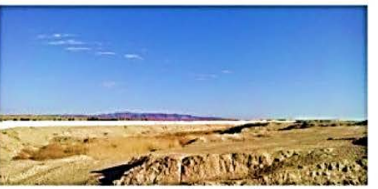

picture 5

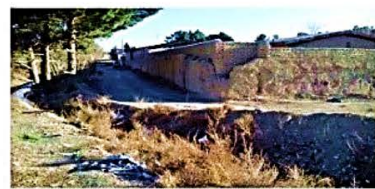

picture 7

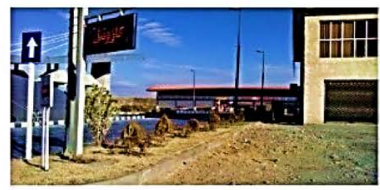

picture 9

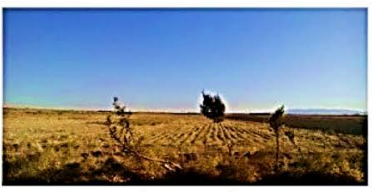

Agricultural Zone

picture 2

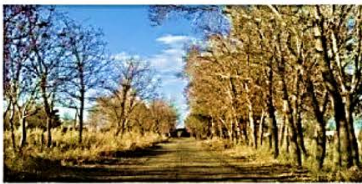

picture 4

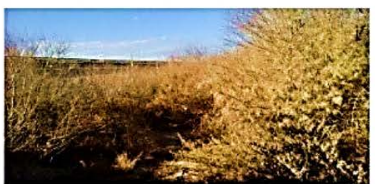

picture 6

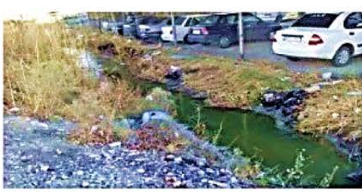

picture 8

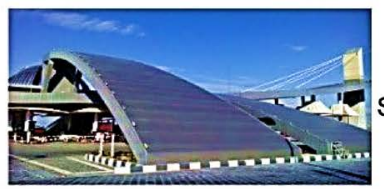

picture 10

Zone

Salt River

Zone

Industrial

Zone

Welfare

Services Zone

Figure 5. Selected photographs from different areas of the region were examined to evaluate the visual quality of the landscape.

Also, in this research 30 questionnaires were considered based on the Q-Sort method and Delivered to users.

\section{Results}

The completed questionnaires were given to users and they were asked to rate it on the cards according to the number of each photo, then using the equation 1 , the scores mean were calculated for each photograph. The results are presented in Table 1.

Finally, the utility criteria and non-desirability criteria in the target area were extracted [24], and presented in Table 2.

According to the obtained criteria and landscape preferences from the viewpoint of the users, exact operational objectives, strategies and policies for design were identified and the necessary steps were taken to achieve these goals. Finally, the strategic plan of the study area was extracted from these policies, which presented in Table 3.

There are different approaches regarding landscape design which leads to interaction between human and environment. The strategic plan, with a compre- 
Table 1. Averages obtained from users opinions on taken photographs.

\begin{tabular}{|c|c|c|c|c|c|c|c|c|c|}
\hline \multicolumn{10}{|c|}{ The number of people choosing each photo in different qualities (30 users) } \\
\hline & $\begin{array}{l}\text { Photo } \\
\text { number }\end{array}$ & Very beautiful & Beautiful & Normal & Ugly & Very ugly & $\begin{array}{l}\text { Photo's } \\
\text { Score }\end{array}$ & $\begin{array}{l}\text { Average } \\
\text { scores }\end{array}$ & $\begin{array}{c}\text { Average rating } \\
\text { of each zone }\end{array}$ \\
\hline \multirow{2}{*}{ Agricultural zone } & 1 & 16 & 9 & 5 & 0 & 0 & 41 & 1.36 & \multirow{2}{*}{1.16} \\
\hline & 2 & 9 & 12 & 8 & 1 & 0 & 29 & 0.96 & \\
\hline \multirow{2}{*}{ Natural zone } & 3 & 8 & 7 & 13 & 2 & 0 & 21 & 0.7 & \multirow{2}{*}{1.13} \\
\hline & 4 & 21 & 5 & 4 & 0 & 0 & 47 & 1.56 & \\
\hline \multirow{2}{*}{ Salt river zone } & 5 & 9 & 5 & 12 & 4 & 0 & 19 & 0.63 & \multirow{2}{*}{0.93} \\
\hline & 6 & 13 & 11 & 6 & 0 & 0 & 37 & 1.23 & \\
\hline \multirow{2}{*}{ Industrial zone } & 7 & 0 & 2 & 8 & 17 & 3 & -21 & -0.7 & \multirow{2}{*}{-1.08} \\
\hline & 8 & 0 & 0 & 5 & 6 & 19 & -44 & -1.46 & \\
\hline \multirow{2}{*}{ Welfare services zone } & 9 & 0 & 2 & 19 & 6 & 3 & -10 & -0.33 & \multirow{2}{*}{-0.245} \\
\hline & 10 & 0 & 9 & 17 & 4 & 0 & -5 & -0.16 & \\
\hline
\end{tabular}

Table 2. Utility or inappropriateness criteria for spaces obtained from the user's point of views.

\begin{tabular}{cc}
\hline Utility criteria & Non-utility criteria \\
\hline Being pristine and natural & Lack of green space \\
Vegetation diversity & Visual perturbation in space \\
Space composition & The existence of human elements \\
Having a sense of place & Inappropriate composition of spaces \\
Quality of green space & Insecure and dark spaces \\
\hline
\end{tabular}

Table 3. Sustainable ecological landscape design measures and policies.

\begin{tabular}{|c|c|c|c|}
\hline 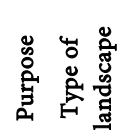 & 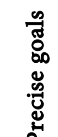 & 芯 & $\begin{array}{l}\overline{0} \\
0 \\
0\end{array}$ \\
\hline
\end{tabular}

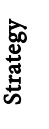

\begin{tabular}{|c|c|c|c|c|c|}
\hline & 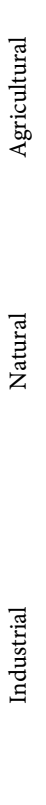 & $\begin{array}{l}\text { - Searching for a Proper natural } \\
\text { pattern } \\
\text { - Save open sights } \\
\text { - considering the ecological needs } \\
\text { of the plants } \\
\text { - Protecting plants as one of the } \\
\text { factors contributing to micro- } \\
\text { climate } \\
\text { - Focusing on the ecological } \\
\text { framework in design } \\
\text { - The harmony between natural } \\
\text { and human elements } \\
\text { - Reduction of contaminations } \\
\text { which caused by human elements }\end{array}$ & $\begin{array}{l}\text { - Use of native plants to strengthen } \\
\text { vegetation } \\
\text { - Windscreen construction to prevent } \\
\text { wind erosion } \\
\text { - Use of biological methods to control } \\
\text { pests and existing plant diseases } \\
\text { - Creating ecotourism spaces } \\
\text { - Design using indigenous materials in } \\
\text { harmony with the environment } \\
\text { - Using echo technical methods } \\
\text { - Planting shady trees along the way } \\
\text { (helping to prevent erosion) }\end{array}$ & $\begin{array}{l}\text { - Strengthening existing ecosystems } \\
\text { and trying to protect them } \\
\text { - Emphasis on the micro climate } \\
\text { created in agricultural lands and } \\
\text { strengthening of them } \\
\text { - Support of local agriculture } \\
\text { - Variation color using vegetation } \\
\text { in accordance with the } \\
\text { environment } \\
\text { - Creating soft bodies in accordance } \\
\text { with the natural bed of the earth } \\
\text { - Protecting slopes and high quality } \\
\text { soils }\end{array}$ & $\begin{array}{l}\text { - Using a comprehensive design } \\
\text { approach } \\
\text { - Development and protection of } \\
\text { farms } \\
\text { - Using existing potential in the } \\
\text { environment to reduce pollution } \\
\text { Taking into account the talents and } \\
\text { potential of the environment } \\
\text { - Focusing on the natural processes as } \\
\text { the basis of design } \\
\text { - Formulation of principles and rules } \\
\text { on how to intervene in open spaces } \\
\text { based on landscape typography } \\
\text { - Control of carried out constructions } \\
\text { - Creating a harmony between human } \\
\text { elements and natural space with } \\
\text { building proper bodies } \\
\text { - Avoiding the drainage of sewage in } \\
\text { the streams } \\
\text { - Preventing the land use conversion }\end{array}$ \\
\hline
\end{tabular}




\section{Continued}

\begin{tabular}{|c|c|c|c|c|}
\hline 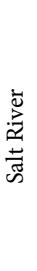 & $\begin{array}{l}\text { A more comprehensive view of the } \\
\text { river from different } \\
\text { environmental points of view } \\
\text { - Maintaining the vegetation of } \\
\text { surroundings of the river }\end{array}$ & $\begin{array}{l}\text { - Repairing and completion of drainage } \\
\text { system } \\
\text { - Observing and handling of existing } \\
\text { plants on the river's margin } \\
\text { - Designing the proper route for sewage } \\
\text { and preventing them from entering the } \\
\text { river }\end{array}$ & $\begin{array}{l}\text { - Emphasizing on the elements of } \\
\text { the site and using of them to give } \\
\text { identity to the environment } \\
\text { - Creating visual variation } \\
\text { combined with visual integration } \\
\text { in design } \\
\text { - Give identity to the landscape } \\
\text { around the river }\end{array}$ & $\begin{array}{l}\text { - preventing degradation of } \\
\text { environmental structures in order to } \\
\text { avoid disruption in their operation } \\
\text { - Coordination of planting vegetation } \\
\text { cover with native vegetation } \\
\text { - Maintaining biodiversity and } \\
\text { complexity of the regional structure }\end{array}$ \\
\hline 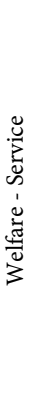 & $\begin{array}{l}\text { - Continuity of environment } \\
\text { consistency and designed } \\
\text { landscapes with environmental } \\
\text { structures } \\
\text { - Noticing to users and supervisors } \\
\text { as design participants }\end{array}$ & $\begin{array}{l}\text { - Increasing board activities such as } \\
\text { pharmacy, supermarkets } \\
\text { - Standard light and standard lighting } \\
\text { especially in vulnerable spaces } \\
\text { - Improving and optimizing the paths of } \\
\text { motion }\end{array}$ & $\begin{array}{l}\text { - Beautifying and showcasing on } \\
\text { footpaths } \\
\text { - Providing recreational facilities } \\
\text { such as parking, pausing spaces } \\
\text { and... } \\
\text { - Using proper furniture fitting } \\
\text { with the view } \\
\text { - Establishing appropriate spaces } \\
\text { for the accumulation of waste at } \\
\text { specified intervals, taking into } \\
\text { account all environmental issues } \\
\text { in indoor enclosures. }\end{array}$ & $\begin{array}{l}\text { - Design which is consistent with } \\
\text { natural and human ecosystems } \\
\text { - Landscape architecture for serving } \\
\text { users and observers and meeting } \\
\text { their needs } \\
\text { - Efforts to reduce energy } \\
\text { consumption }\end{array}$ \\
\hline
\end{tabular}

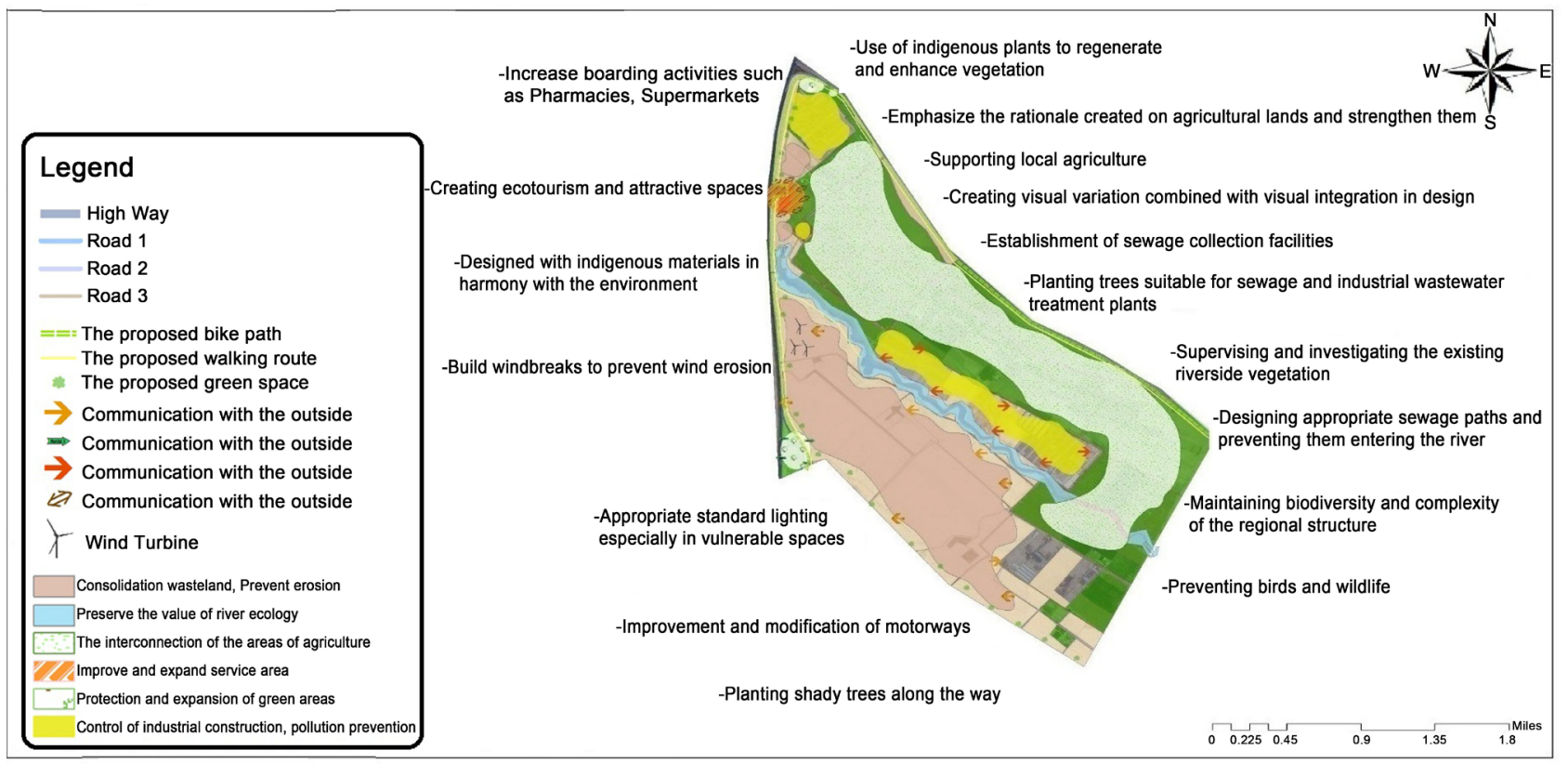

Figure 6. Strategic design based on spatial desirability criteria for study area.

hensive, integrated and mosaic view, strives to preserve the integrity of the ecological characteristics of the area, and by avoiding the fragmentation of the arena, it has a reconstructive and restorative view towards landscape improvement. Hence, by presenting a strategic plan, we can organize planned actions and policies together in a plan. The strategic design is shown in Figure 6.

\section{Discussion}

In this report, we tried to describe a case-by-case example of the Q-sorter method for landscape assessment, from the perspective of users of this landscape, and to identify the indicators of desirability and disadvantage of the landscape 
by using beauty and unbeauty of landscape. One of the most influential factors in improving the visual quality of the landscape is the attention to proper design of the spaces and the harmony of these spaces with the users otherwise, it becomes the most important visual disturbance factor in the landscape. The use of vegetation as the main factor in making landscapes is very important. Having a variety of green spaces in the environment creates a sense of location, tranquility and proximity to nature among people.

Considering the role of landscape analysis in design, it can be a great solution to achieve user satisfaction. Using the results of landscape analysis, we can identify spatial desirability and undesirability components and take the necessary steps to achieve design goals from this section.

The findings of this study indicate that users were more comfortable with the spaces of more diverse vegetation. Also, human elements which were contrary to the nature of the region and were not well suited to the surrounding environment were criticized by most of landscape users. In fact, in view of users, the beautiful landscape is included with diverse vegetation with shady space, suitable color combination and away from any visual disturbance. On the contrary, in their view, ugly landscape is one in which human elements make improper compositions and also include visual disturbance which leads to unpleasant landscape.

In this study, in order to improve the quality of the landscape in five study areas based on the survey, the following suggestions are available:

In the agricultural zone, by the use of indigenous plants to revitalize and enhance vegetation, the use of products with low water requirements and construction of a windscreen to prevent wind erosion, we can improve this type of landscape.

In the industrial zone, by minimizing the negative environmental consequences of production patterns, we should attempt to organize industrial waste to help the environment and landscape of the region.

In the natural zone, using indigenous materials which are in harmony with the environment, as well as protecting the slopes and fertile soils, we can have a beautiful landscape.

In the shore of the river preventing wind erosion is the most important environmental action that can be achieved by preserving the biodiversity of plant and animal life in the area. Finally, in the area of service-welfare, beauty and symbolism in the paths and creating recreational-welfare facilities can be very effective in organizing this arena.

The present article, natural landscaping and planting design of indigenous plants which are resistant to climatic conditions of the area, considered the prevention of wind erosion in the design of the landscape. This was done to create various landscape and diverse spaces for the landscape users.

This process was completed by ecological qualitative analysis, which was considered for each zone of landscape, and finally, using the results of landscape analysis was used in the landscape. 


\section{Conclusion}

The use of functional approaches such as Q-Sort in landscape analysis can be used to determine the spatial desirability criteria, so that it can create a sense of place and belonging in design and will design suitable spaces for use by the general public. In the meantime, the use of qualitative and ecological analysis will be effective. In order to further enhance and complete the studies, this study suggests that in future studies, landscape analysis and ecological analysis are better to be used in combination and in common to respond to the needs of the natural and human environment.

\section{References}

[1] Shafer, E., Hamilton, J. and Schmidt, E. (1969) Natural Resources Preferences: A Predictive Model. Journal of Leisure Resources, 1, 1-19.

[2] Palmer, J.F. (2004) Using Spatial Metrics to Predict Scenic Perception in a Changing Landscape: Dennis, Massachusetts. Landscape and Urban Planning, 69, 201-218. https://doi.org/10.1016/j.landurbplan.2003.08.010

[3] Johnston, S.W. and Growcock, A.J. (2005) Visiting the Kosciuszko Alpine Area: Visitor Numbers, Characteristics and Activities. CRC for Sustainable Tourism Pty Ltd., Sydney.

[4] Farias, E.I., Ricardo Grau, T.H. and Camps, A. (2005) Trail Preferences and Visitor Characteristics in Aigüestortes i Estany de Sant Maurici National Park, Spain. Journal of Mountain Research and Development, 25, 51-59. https://doi.org/10.1659/0276-4741(2005)025[0051:TPAVCI]2.0.CO;2

[5] Hettinger, N. (2007) Objectivity in Environmental Aesthetics and Protection of the Environment. In: Carlson, A. and Lintott, S., Eds., Beauty to Duty: From Aesthetics to Environmentalism. In Columbia University Press, New York.

[6] Dearden, P. (1985) Philosophy, Theory and Method in Landscape Evaluation. Canadian Geographer, 29, 263-265. https://doi.org/10.1111/j.1541-0064.1985.tb00371.x

[7] Burley, B.J. (2006) A Quantitative Method to Assess Aesthetic/Environmental Quality for Spatial Surface Mine Planning and Design Applications. Transactions on Environment and Development, 2, 524-529.

[8] Panagopoulos, T. (2009) Linking Forestry, Sustainability and Aesthetics. Ecological Economics, 68, 2485-2489. https://doi.org/10.1016/j.ecolecon.2009.05.006

[9] Daujotaite, I. (1998) Topics of Landscape Architecture. Vilnius University Publication, Vilnius, 91.

[10] Lothian, A. (1999) Landscape and the Philosophy of Aesthetics: Is Landscape Duality Inherent in the Landscape or in the Eye of Beholder? Landscape and Urban Planning, 44, 177-198. https://doi.org/10.1016/S0169-2046(99)00019-5

[11] Kane, P.S. (1981) Assessing Landscape Attractiveness: A Comparative Test of Two New Methods. Applied Geography, 1, 77-96. https://doi.org/10.1016/0143-6228(81)90027-8

[12] Rafiani Khachak, P., Mohammadzadeh, M. and Mirkarimi, H. (2014) Visual Assessment of Landscape Quality Based on Perceptual Approach, a Model for More Desirable Management of Recreational Areas (Case Study: Walking Trails in Ziarat Watershed of Gorgan). Journal of Environmental Research, 19, 3-14. 
[13] Kaplan, S. and Kaplan, R. (1989) The Visual Environment: Public Participation in Design and Planning. Journal of Social Issues, 45, 59-86. https://doi.org/10.1111/j.1540-4560.1989.tb01533.x

[14] Golchin. P., Narouee B. and Masnavi, M. (2012) Evaluation of Visual Quality of Educational Spaces Based on User Preferences (Case Study: Sistan and Baluchestan University). Journal of Ecology, 13, 135-150.

[15] Avizien, D., Pakalnis, R. and Sendzikaite, J. (2007) Preservation, Assessment and Management of Scenic Landscape in Lithuania. Man in the Landscape across Frontiers-IGU-LUCC Central Europe Conference, Slovenia, Austria, Slovakia and the Czech Republic, 2007, 8-19.

[16] Nami, P., Jahanbakhsh, P. and Fathalipour, A. (2016) The Role and Heterogeneity of Visual Pollution on the Quality of Urban Landscape Using GIS; Case Study: Historical Garden of Maraqeh. Open Journal of Geology, 6, 20-29.

https://doi.org/10.4236/ojg.2016.61003

[17] do Couto Fernandes, M., dos Santos, T.L.C., Coura, P.H.F., de Menezes, P.M.L. and Graça, A.J.S. (2013) Modeled Surface Observations for Spatial Analysis of Landscape Dynamics. Journal of Geographic Information System, 5, 409-417. https://doi.org/10.4236/jgis.2013.54039

[18] Lipovská, B. and Štěpánková, R. (2013) Assessing Observation Methods for Landscape Planning Practice in Rural Villages. Current Urban Studies, 1, 102-109. https://doi.org/10.4236/cus.2013.14011

[19] Iran Meteorological Organization (2016) Meteorological Data and Maps of Tehran Province, Imam Khomeini Airport Station. http://www.irimo.ir/eng/wd/720-Products-Services.html\#report builder form

[20] Simon, B. (1999) Landscape: Pattern, Perception and Process. Taylor and Francis, Abingdon, 344.

[21] Herrington, N. and Coogan, J. (2011) Q Methodology: An Overview. Research in Secondary Teacher Education, 1, 24-28.

[22] Khoshgooyan Fard, A. (2007) Q-Methodology. Tehran Soroush Publication, Teh$\tan , 252$.

[23] Motevalli. M. (2010) Determining the Quality of Beauty in Urban Landscape Based on the Concept of Consecutive Views (Case Study: Darabad Tourist Road, Tehran). Armanshahr Magazine, 4, 123-139.

[24] Darabi, H. (2016) Course Notes of Landscape Recognition and Analysis. Faculty of Environment, University of Tehran, Tehran, 85. 
Submit or recommend next manuscript to SCIRP and we will provide best service for you:

Accepting pre-submission inquiries through Email, Facebook, LinkedIn, Twitter, etc. A wide selection of journals (inclusive of 9 subjects, more than 200 journals)

Providing 24-hour high-quality service

User-friendly online submission system

Fair and swift peer-review system

Efficient typesetting and proofreading procedure

Display of the result of downloads and visits, as well as the number of cited articles Maximum dissemination of your research work

Submit your manuscript at: http://papersubmission.scirp.org/

Or contact oje@scirp.org 